\title{
Organic Pollutants Photo-Degradation by Steady g- C3N4 Nanorods for Wastewater Treatment Applications
}

\section{Nafisa Malik}

University of Gujrat

Abdul Majid

Majmaah University

Ghulam Nabi ( $\sim$ gnwattoo@yahoo.com )

University of Gujrat https://orcid.org/0000-0001-9311-1233

Marlia M. Hanafiah

Universiti Kebangsaan Malaysia

\section{Thamer Alharbi}

Institute of Physics, Technical University of Ilmenau

\section{Mansour Al-Habardi}

Institute of Physics, Technical University of IImenau

\section{Waseem Raza}

University of Gujrat

\section{Wajid Ali}

University of Gujrat

\section{Research Article}

Keywords: Degradation, g-C3N4, Nano-rods, Organic dyes, Waste water

Posted Date: September 29th, 2021

DOl: https://doi.org/10.21203/rs.3.rs-930377/v1

License: (1) (1) This work is licensed under a Creative Commons Attribution 4.0 International License. Read Full License 


\title{
Organic Pollutants Photo-degradation by Steady g- $\mathrm{C}_{3} \mathrm{~N}_{4}$ Nanorods for Wastewater Treatment Applications
}

Nafisa Malik ${ }^{\mathrm{a}}$, Abdul Majid ${ }^{\mathrm{b} *}$, Ghulam Nabi $^{\text {a.c** }}$, Marlia M. Hanafiah ${ }^{\mathrm{d}}$, Thamer Alharbi ${ }^{\mathrm{c}}$, Mansour Al-Habardi ${ }^{\mathrm{c}}$, Waseem Raza ${ }^{\mathrm{a}}$ Wajid Ali ${ }^{\mathrm{a}}$

${ }^{a^{*}}$ Nanotechnology Lab, Department of Physics, University of Gujrat, Gujrat, Pakistan.

b** $^{* *}$ Department of Physics, Faculty of Science, Majmaah University, Majmaah, 11952, Saudi Arabia.

c* Institute of Physics, Technical University of Ilmenau, Ilmenau 98693, Germany.

${ }^{\mathrm{d}}$ Department of Earth Sciences and Environment, Faculty of Science and Technology, Universiti Kebangsaan Malaysia, 43600, Bangi, UKM, Selangor, Malaysia.

*Corresponding Author, Email: gnwattoo@yahoo.com (Dr. Ghulam Nabi) Tel: +92-3339976929

***. Abdul Majid (a.abdulmajid@mu.edu.sa)

\begin{abstract}
The photo-catalysis is a promising method for the degradation of harmful organic pollutants existing in the wastewater. In this research work, degradation of organic pollutants (dyes) have been done proficiently for the wastewater treatment applications. The synthesized steady graphitic carbon nitride $\left(\mathrm{g}-\mathrm{C}_{3} \mathrm{~N}_{4}\right)$ nanorods have been examined by various sophisticated characterization techniques such as XRD, SEM, EDS, TEM, UV-Vis and PL. The hexagonal phase of $\mathrm{g}-\mathrm{C}_{3} \mathrm{~N}_{4}$ has been showed in XRD analysis. SEM shows that the morphology of $\mathrm{g}-\mathrm{C}_{3} \mathrm{~N}_{4}$ consists of aggregated nanorods. The EDS depicting only two peaks which are carbon and nitrogen and nitrogen without impurities. According to the study of UV-Visible and PL, $2.77 \mathrm{eV}$ band gap has been observed showing consistency. The steady g- $\mathrm{C}_{3} \mathrm{~N}_{4}$ nanorods have been used for the degradation of prominent organic dyes such as: methylene orange (MO), methylene blue (MB) and rhodamine-B (Rh-B) for treatment of wastewater which is a dire need. The effect of catalyst mass loading and time have been studied for this purpose. This research depicted that the
\end{abstract}


anion $\left(\cdot \mathrm{O}^{2}-\right)$ and holes $\left(\mathrm{h}^{+}\right)$are attributed to the degradation of organic pollutants. whose Rh-B, MB and MO dyes. Research based a tentative photocatalytic mechanism has also been proposed for waste treatment purpose.

\section{Key Words}

Degradation, $\mathrm{g}-\mathrm{C}_{3} \mathrm{~N}_{4}$, Nano-rods, Organic dyes, Waste water

\section{Introduction}

Graphitic carbon nitride has been explored as a metal-free photo-catalyst for the water purification. It has extensive applications for organic compounds and also degradation of organic pollutants under the visible light. The band gap of graphitic carbon nitride $\left(g-C_{3} N_{4}\right)$ has been calculated 2.7-2.8eV. It has superior thermal and chemical stability, useful optical features, fast charge carrier recombination rate and low solar energy utilization. Various researchers have manipulated the $\mathrm{g}-\mathrm{C}_{3} \mathrm{~N}_{4}$ by various methods including hetero atom doping, thermal treatment, hybridization with other semiconductor and also by using different precursors to improve their structure and properties [1-3]. The improvisation of $\mathrm{g}-\mathrm{C}_{3} \mathrm{~N}_{4}$ played a vital role to improving the photo degradation activity. It has deployed the electronic structure that may act as active sites for reactive molecules and central gap states can also be created when the structure of the semiconductor is defective. The overlapping of valence or conduction band with mid gap states of the semiconductor extends optical response and electrons-hole pair excitation that act as the active sites. These trapping sites can be improved through quantum efficiency of photo-induced carriers $[4,5]$. The $\mathrm{g}-\mathrm{C}_{3} \mathrm{~N}_{4}$ has prepared by using ammonium thiosulfate through hydrothermal method. The process of photo-catalytic enhanced its efficiency due to lack of terminal amino species. 
The $\mathrm{g}-\mathrm{C}_{3} \mathrm{~N}_{4}$ is prepared with concentrated hydrochloric acid having nitrogen vacancies and big surface area which exhibit outstanding $\mathrm{N}_{2}$ photo fixation activity [6-9]. Nevertheless, the structure of $\mathrm{g}_{-} \mathrm{C}_{3} \mathrm{~N}_{4}$ can be ruined through usage of acid and reaction conditions such as the concentration of acid. It is difficult to control the nitrogen vacancies due to the high synthesis temperature of $\mathrm{g}_{-} \mathrm{C}_{3} \mathrm{~N}_{4}$. Consequently, it is interesting and exhilarating to discover the new concrete and facile treatment for formulating nitrogen-deficiency from $g-\mathrm{C}_{3} \mathrm{~N}_{4}$ and the activity of photo-catalytic can be improved in limited way [10, 11].

The graphitic carbon nitride has vast applications. It is generally used as an organic dye degradation agent in different industries such as textiles, tannery, food and cosmetics etc [12-15]. Having all these benefits, the removal of pollutants has attracted growing consideration to worldwide, although it utilization maybe limited due to its high solubility and atmospheric risk. Commonly, methylene blue (MB) is a common constituent of industrial wastewater contaminants. Its constant use burns to humans and animals' eyes, nausea, vomiting, profuse sweating, nervous system disorder, and methemoglobinemia [16-24]. In the recent century, photo-catalytic treatment has increased the abundant concerns because of its ease, low cost, easy operation and ease of being reused after completion of the reaction (because catalyst can be easily separated) $[25,26]$. To improve the photo-catalytic activity, performance-based nano composites have been established by combination of $\mathrm{g}-\mathrm{C}_{3} \mathrm{~N}_{4}$ with extra types of inorganic photocatalysts [27-30]. However, utmost of these variations possess some further disadvantages, such as tedious artificial steps, etc [31, 32]. Therefore, it is essential to accept a novel metal-free photo-catalytic material and easily recoverable degradation of organic pollutants [33-36].

Herein, novel metal-free $\mathrm{g}-\mathrm{C}_{3} \mathrm{~N}_{4}$ nanorods have been synthesized by facile and simple calcination process. Various sophisticated analysis techniques have been employed to analyze its proper 
synthesis, its purity and its effective utilization as an effective photo-catalyst. The two main factors such as catalyst mass loading and time have been comprehensively studied in this research work for effective use in the industries for waste water treatment against methylene orange (MO), methylene blue (MB) and rhodamine-B (Rh-B). This study showed the improvement of the photocatalytic properties of the steady $g-\mathrm{C}_{3} \mathrm{~N}_{4}$ which may be used effectively in the industries for waste water treatment.

\section{Materials and Methods}

\subsection{Prepared of $\mathrm{g}-\mathrm{C}_{3} \mathrm{~N}_{4}$}

Graphitic carbon nitride $\left(\mathrm{g}-\mathrm{C}_{3} \mathrm{~N}_{4}\right)$ nanorods have been synthesized by a simple calcination method through urea. Six gram $(6 \mathrm{~g})$ urea was taken and placed in crucible china dish, which covered with an alumina sheet later on. This product is kept in a furnace and heated at the temperature of $550^{\circ} \mathrm{C}$ for 2 hours. After that sample was cooled down to room temperature and then the product was annealed at $450{ }^{\circ} \mathrm{C}$ for 1 hour. Finally, the product was obtained as yellow-pale color in powder form as predicted in Fig.1. The whole synthesis process has been depicted in the Fig. 1

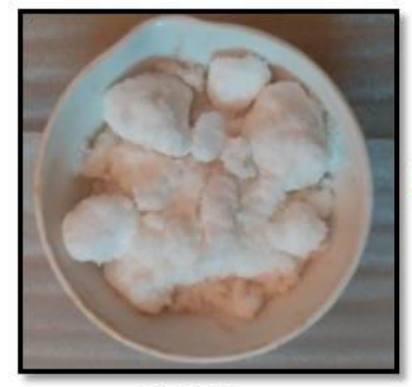

6g Urea

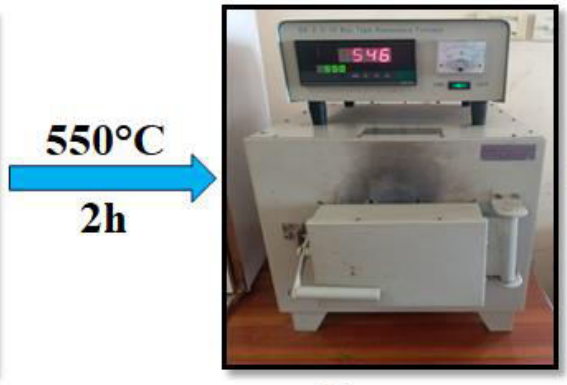

Furnace

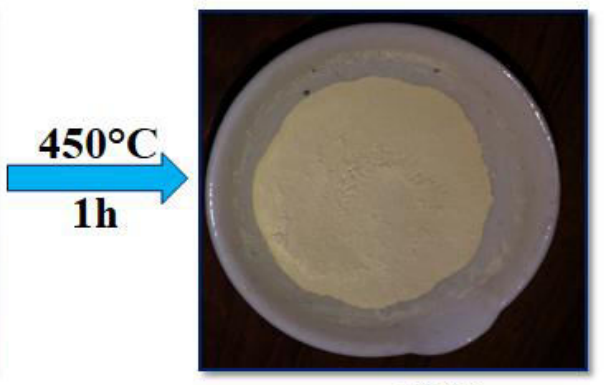

$\mathrm{g}-\mathrm{C}_{3} \mathrm{~N}_{4}$

Fig. 1: Schematic diagram of the preparation of $\mathrm{g}-\mathrm{C}_{3} \mathrm{~N}_{4}$ from through urea. 


\subsection{Materials Characterizations}

The prepared samples $\left(\mathrm{g}-\mathrm{C}_{3} \mathrm{~N}_{4}\right)$ were characterized by diverse techniques. X-rays powder diffractometer have been used to examine the X-ray diffraction (XRD) pattern with $\mathrm{Cu}-\mathrm{K} \alpha$ radiation source $(\lambda=0.15418 \mathrm{~nm})$. The surface morphology of $\mathrm{g}-\mathrm{C}_{3} \mathrm{~N}_{4}$, nanorods have been analyzed by scanning electron microscopy (SEM), ZESIS-V80 which is equipped with the energy dispersive X-rays spectroscopy (EDX) technique toward study the fundamental elemental conformation of the prepared samples. For insight study TEM was performed with JEOL JEM-2100 model. The photoluminescence (PL) measurements were studied by using JASCO model number FP-8200 spectrometer.

\subsection{Photo-catalytic performance of organic dye}

The photo-degradation of $\mathrm{g}_{-} \mathrm{C}_{3} \mathrm{~N}_{4}$ organic dye (Methylene Orange, Rhodamine-B and Methylene Blue was done. The $200 \mathrm{~W}$ xenon lamps was used and on two opposite side walls of the reactor as simulated solar irradiation source. The aqueous solution of $\mathrm{g}-\mathrm{C}_{3} \mathrm{~N}_{4}$ by was prepared by adding $0.1 \mathrm{~g}$ catalyst and dissolved in $250 \mathrm{ml}$ of distilled water. The above solution has continuous stirring for 30 minutes at room temperature to attain adsorptiondesorption equilibrium. At regular time intervals, $2 \mathrm{ml}$ of suspensions were drawn out during the irradiation process. To separate this solution, centrifuged samples were taken immediately by using UV-Visible Spectrophotometer. It has wavelength range of 300 to $800 \mathrm{~nm}$ in the visible light of region. The same treatment was done for the other two dyes (MB and Rh-B). Degradation efficiency $(\eta)$ of photo-catalytic of three organic dyes have been obtained by using following equation 1 :

$\eta=\left(\mathrm{C}_{0}-\mathrm{C} / \mathrm{C}_{\mathrm{o}}\right) \times 100 \%$ 
Where $\mathrm{C}_{\mathrm{o}}$ is representing the solution initial concentration with respect to dyes, $\mathrm{C}$ is the concentration of the dyes solution at reaction time $\mathrm{t}[37,38]$. For finding the apparent rate constant $(\mathrm{K})$, the equation of pseudo-first-order kinetic energy is used as following equation 2:

$\operatorname{Ln}\left(\mathrm{C}_{\mathrm{O}} / \mathrm{C}_{\mathrm{t}}\right)=\mathrm{Kt}$.

\section{Results and Discussion}

\section{FESEM, TEM and EDS Analysis}

The morphology of the synthesized sample has been studied through scanning electron microscope as depicted in Fig. 2(a). The FESEM confirmed that the nano fibers like structures are present with almost uniform diameter with a smooth surface. In the FESEM some agglomeration has also been observed in the nanorods. The dimeter of the nanorods is observed 200-400 nm whereas their length in in microns. The results of TEM also showed the nano fibers range of $200 \mathrm{~nm}$ with a smooth surface as shown in Fig. 2(b) which supports the FESEM results. For elemental analysis, Energy-dispersive X-ray spectroscopy (EDX) has been used. The elemental analysis confirmed that only two peaks of carbon and nitrogen are present. No other impurity peaks have been observed such as oxygen, which shows the successful growth of g- $\mathrm{C}_{3} \mathrm{~N}_{4}$ nanorods. The atomic and weight percentage of $\mathrm{g}-\mathrm{C}_{3} \mathrm{~N}_{4}$ have been showed in the inset of Fig. 2(c) which are consistent with the literature. 

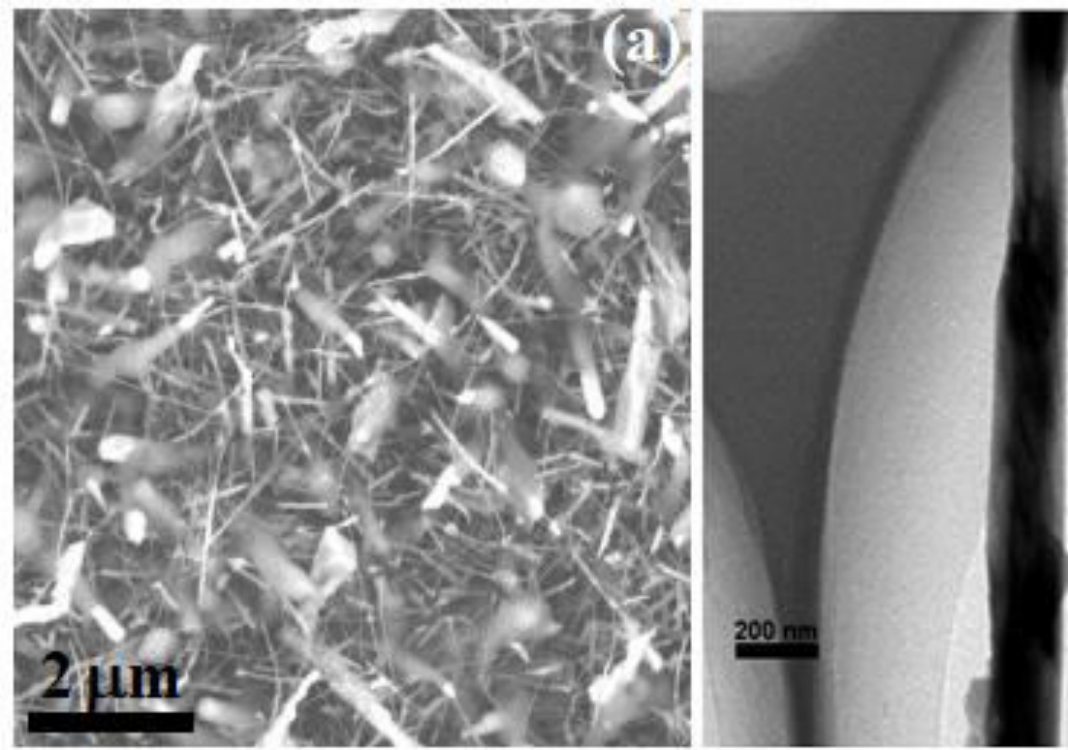

(b)

Full scale counts: 112

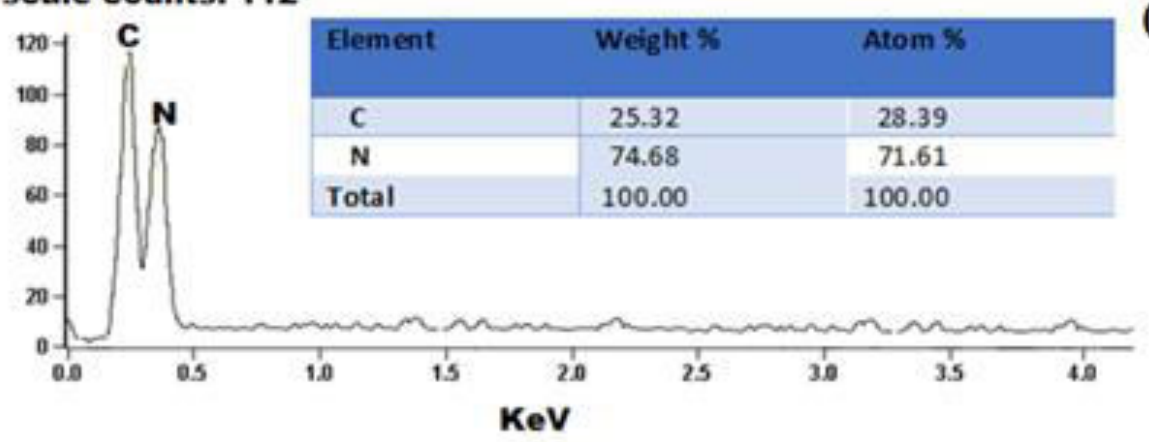

(c)

Fig: 2 (a) FESEM of $\mathrm{g}-\mathrm{C}_{3} \mathrm{~N}_{4}$ nanorods (b) TEM of as prepared $\mathrm{g}-\mathrm{C}_{3} \mathrm{~N}_{4}$ (c) EDS of $\mathrm{g}-\mathrm{C}_{3} \mathrm{~N}_{4}$ whereas inset is the weight and atomic percentage.

\section{XRD Analysis}

$\mathrm{XRD}$ analysis has been done to observer the structure and size distribution of prepared sample as depicted in Fig. 3. One strong peak has been observed at $27.9^{\circ}$ with split head at high intensity which are corresponding to the JCDPS card number (00-003-0401) with miller indices (002). The observed phase group of $(\mathrm{P} 61 / \mathrm{mmc})$ and space group number 192 has hexagonal phase structure. Lattice constants are $\mathrm{a}=\mathrm{b}=3.096 \AA, \mathrm{c}=5.1300 \AA$ and its cell volume is $92.93 \mathrm{~g} / \mathrm{cm}^{3}$. The sharp peaks also confirmed the crystalline nature of the sample. 


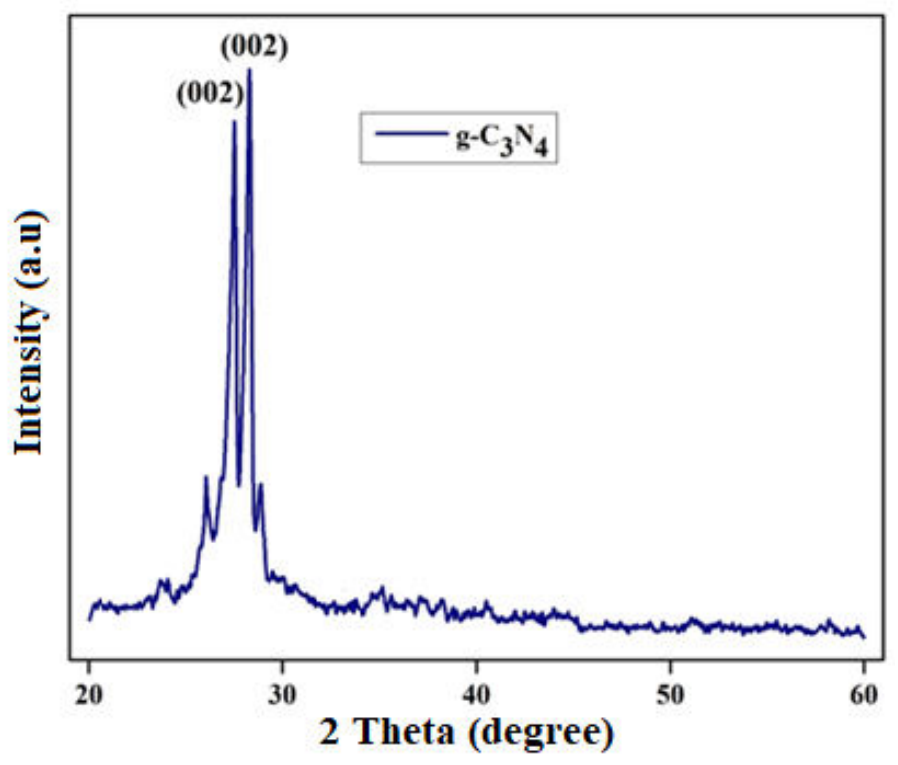

Fig: 3 XRD spectrum of as prepared $\mathrm{g}-\mathrm{C}_{3} \mathrm{~N}_{4}$ nanorods.

The average crystallite size of $\mathrm{g}-\mathrm{C}_{3} \mathrm{~N}_{4}$ nanorods was calculated by using the well-known Debye-Scherrer formula depicted here in equation 3 [39].

$\mathrm{D}=\frac{k \lambda}{\beta \cos \theta}$

Where $\mathrm{k}$ represents Scherrer constant $(\mathrm{k}=0.89), \lambda$ wavelength of $\mathrm{X}$-ray, $\beta$ full width half maximum (FWHM), D being the crystallite size and $\theta$ represents the angle of X-ray diffraction peak. By using this formula calculated the lattice parameter of the prepared samples of different compositions given in Table- 1 . Whereas, $a=d\left(h^{2}+k^{2}+l^{2}\right)^{1 / 2}$

\section{Table. 1 Calculated various parameters of $\mathrm{g}-\mathrm{C}_{3} \mathrm{~N}_{4}$ nanorods.}

\begin{tabular}{|c|c|c|c|c|}
\hline Illustration & $\begin{array}{c}\text { Band gap } \\
\text { Energy }(\mathrm{eV})\end{array}$ & $\begin{array}{c}\text { Crystallite } \\
\text { Size }(\mathrm{nm})\end{array}$ & $\begin{array}{c}\text { Lattice Parameter } \\
(\AA)\end{array}$ & $\begin{array}{c}\text { The Volume of Unit } \\
\text { Cell }\end{array}$ \\
\hline $\mathbf{g}-\mathbf{C}_{\mathbf{3}} \mathbf{N}_{\mathbf{4}}$ & 2.76 & 13 & 8 & 92.93 \\
\hline
\end{tabular}

\section{Optical Properties and Bandgap Calculation of $\mathrm{g}-\mathrm{C}_{3} \mathrm{~N}_{4}$ nanorods.}

Optical properties are crucial for photocatalytic study as it accredits the number of incident photon absorbed during the photo catalytic process [27-30]. The optical properties of prepared 
samples were analyzed by UV-vis spectroscopy. The absorption spectra and Tauc plot of the prepared samples were shown in the Fig. 4. The UV-vis absorption spectra show that the higher absorption is in the range of $250-400 \mathrm{~nm}$ as shown inset of the Fig. 4.

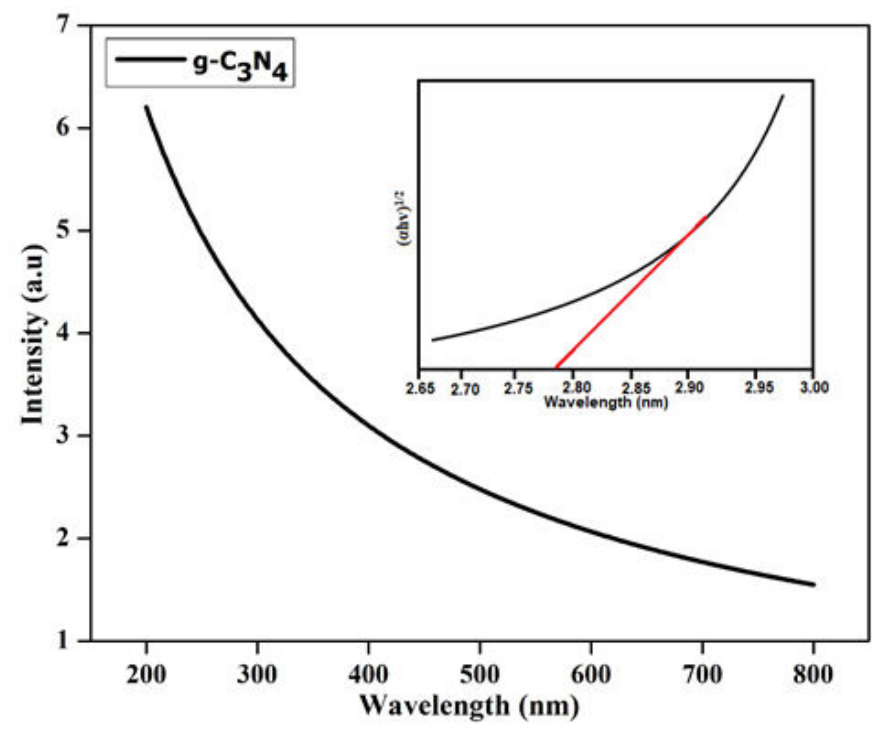

Fig: 4 : UV-visible spectrum of $\mathrm{g}-\mathrm{C}_{3} \mathrm{~N}_{4}$ and inset is the tauc plot.

The band gap of the prepared samples was measured by the following Tauc Eq as depicted in equation 4 .

$\alpha=\mathrm{A}\left(\mathrm{hv}-\mathrm{E}_{\mathrm{g}}\right)^{\mathrm{n} / \mathrm{hv}}$

Where $\alpha$ is the absorption coefficient, A is the proportionality constant, $\mathrm{h} v$ is the incident photon energy and $\mathrm{E}_{\mathrm{g}}$ is the band gap energy. The calculated band gap of $\mathrm{g}^{-} \mathrm{C}_{3} \mathrm{~N}_{4}$ calculated is $2.77 \mathrm{eV}$ at $550^{\circ} \mathrm{C}$ as depicted inset of the Fig.4 which consistent with the literature [27-30, 39].

\section{Photoluminescence (PL)}

The emission properties of $\mathrm{g}_{-} \mathrm{C}_{3} \mathrm{~N}_{4}$ nanorods have been studied by photoluminescence (PL) spectroscopy technique at room temperature. Photoluminescence spectrum of g- $\mathrm{C}_{3} \mathrm{~N}_{4}$ nanorods 
with excitation wavelength of $325 \mathrm{~nm}$ is shown in Fig. 5. A strong and broader emission peak has been observed at $447 \mathrm{~nm}$ for $\mathrm{g}-\mathrm{C}_{3} \mathrm{~N}_{4}$ nanorods which is attributed to band edge emission resulted from the valence band and conduction band recombination of electrons and holes [2730]. The band gap obtained from these $\mathrm{g}-\mathrm{C}_{3} \mathrm{~N}_{4}$ nanorods is $2.77 \mathrm{eV}$ which is consistent with the literature as shown in Fig 5 [39]. Moreover, it is analyzed that there are not any other defects related peaks in synthesized ${ }^{-}-\mathrm{C}_{3} \mathrm{~N}_{4}$. It is well-known that in the bulk phase defects are commonly determined on the surface of the material, which are missing in these $g-C_{3} N_{4}$ nanorods.

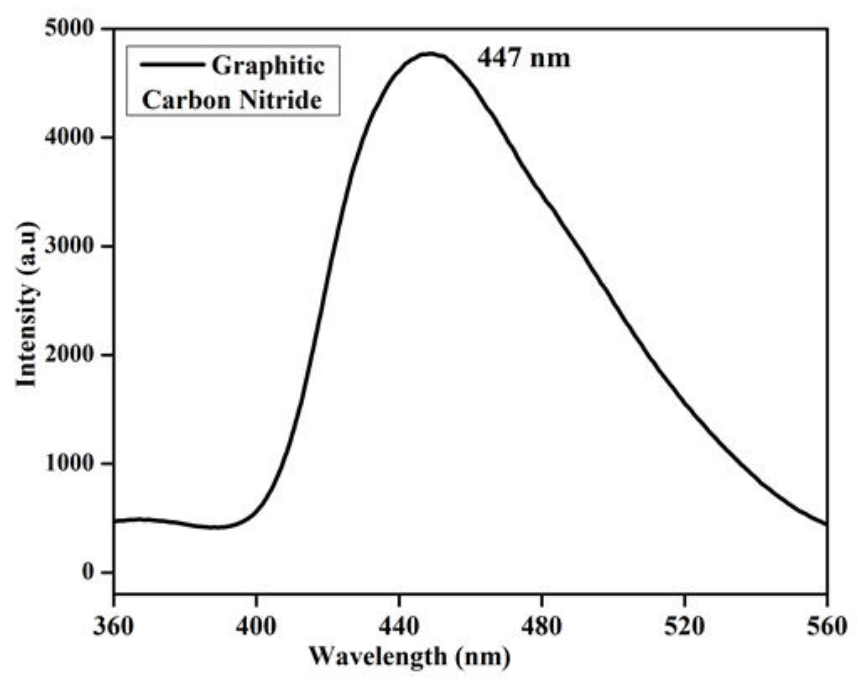

Fig. 5: PL spectrum of $\mathrm{g}-\mathrm{C}_{3} \mathrm{~N}_{4}$ nanorods at room temperature.

\section{Photo-catalytic Performance}

Photo-catalytic degradation of $\mathrm{g}-\mathrm{C}_{3} \mathrm{~N}_{4}$ nanorods under the visible light irradiation $(\lambda \geq 400 \mathrm{~nm})$ of organic dyes, methylene orange (MO), methylene blue (MB) and rhodamine- $\mathrm{B}(\mathrm{Rh}-\mathrm{B})$ dye has been studied comprehensively as depicted in Fig. 6(a-f) with respect to catalyst concentration at

fixed time. 

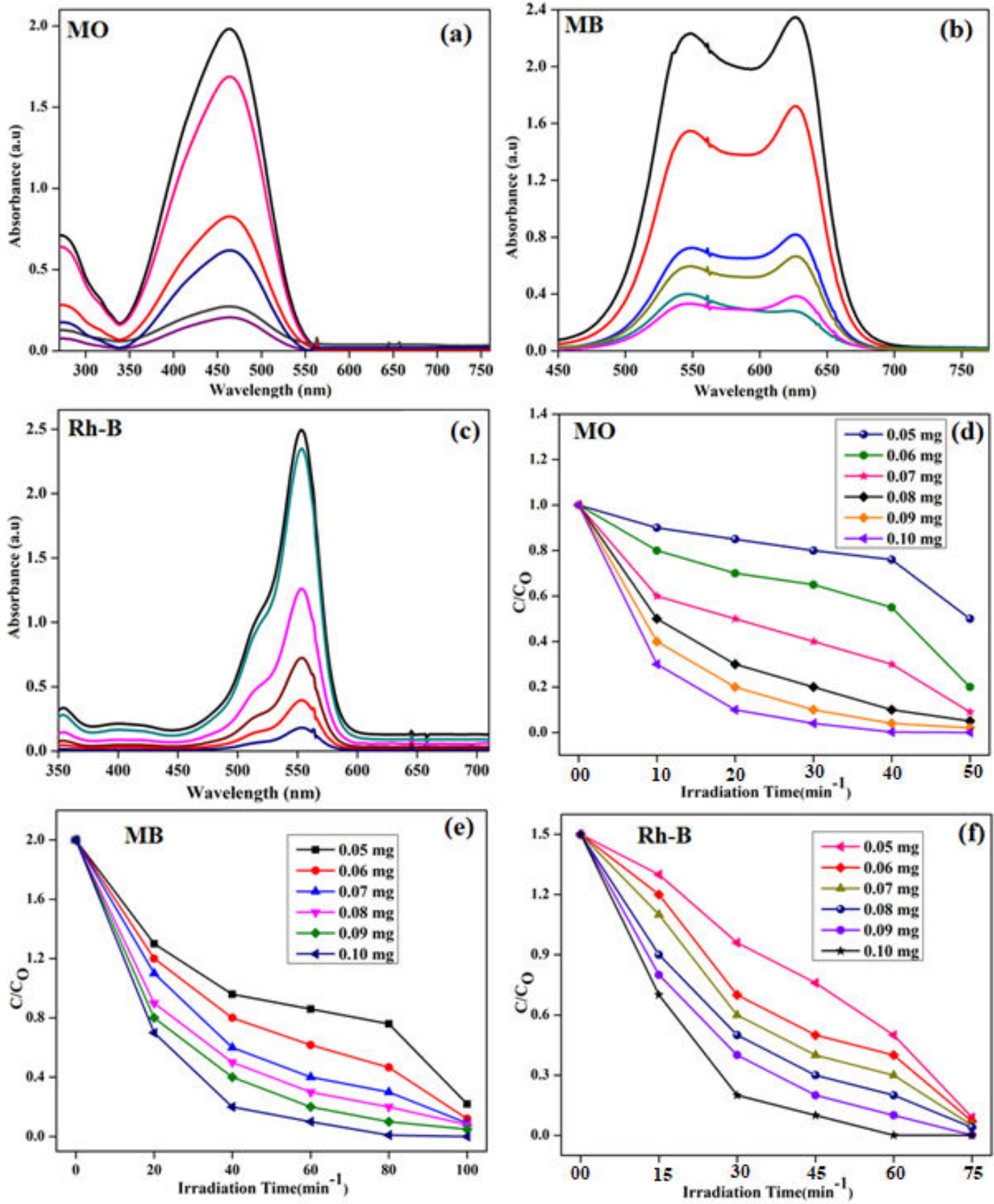

Fig: 6 (a) Degradation of MO dye (b) Degradation of MB dye (c) Degradation of Rh-B dye degradation (d) Graph plotted between the $\mathrm{C} / \mathrm{C}_{0}$ verses irradiation time (methylene orange $\mathrm{MO}$ ) (e) Graph plotted between the $C / C_{0}$ methylene blue (MB) (f) Graph plotted between the $C / C_{0}$ rhodamine-b (Rh-B). 
The catalysts concentration has varied the efficiency of the photo-catalysis as shown in Fig. 6(d, e, f). The prepared $\mathrm{g}-\mathrm{C}_{3} \mathrm{~N}_{4}$ nanorods has degraded $99.6 \%$ methylene orange dye (MO) in 50 minutes. It has also degraded $98 \%$ of methylene blue dye (MB) in 100 minutes, $97.8 \%$ of rhodamine-B (Rh-B) in 75 minutes. The graph has been plotted between the $\mathrm{C}_{0} / \mathrm{C}$ versus time $\mathrm{t}$ for degradation of these organic dyes as depicted in Fig. 6 (d, e, f).

For all these photo-catalysts the graph is also plotted between $\ln \mathrm{C} / \mathrm{C}_{0}$ versus time $\mathrm{t}$ after finding the slope of a straight line. The Pseudo-first-order reaction has been showed as in the linear curve of all samples. The degradation efficiency of g- $\mathrm{C}_{3} \mathrm{~N}_{4}$ nanorods for $\mathrm{MO}$ dye has been verified by the photo-catalytic activity, which is higher because of higher first-order constant. The observed constant rates $(\mathrm{k})$ values are $0.02 \mathrm{~min}^{-1}, 0.06 \mathrm{~min}^{-1}, 0.08 \mathrm{~min}^{-1}, 0.09 \mathrm{~min}^{-1}, 0.10$ $\min ^{-1}$ and $0.14 \min ^{-1}$ as depicted in Fig.7.

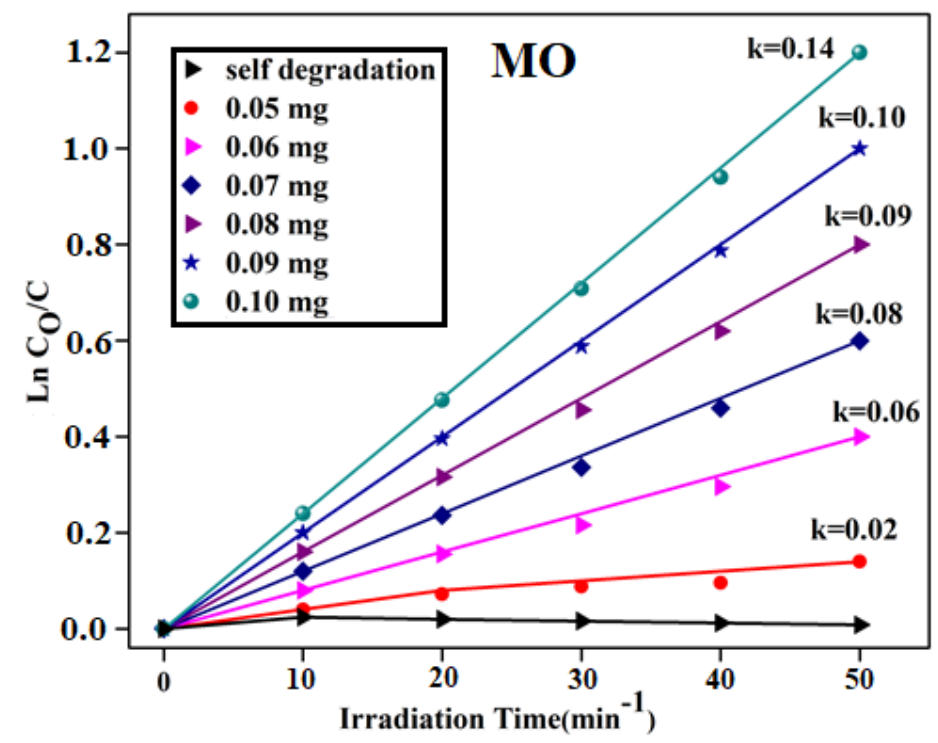

Fig 7: MO graph plotted between the irradiation time and $\ln \mathrm{C}_{0} / \mathrm{C}$ with calculations of $\mathrm{k}$

The pseudo-first-order reaction showed the linear curve for all samples which verified the degradation of MB dyes of the photo-catalytic activity. The graph is plotted between time $t$ and 
$\ln \mathrm{C} / \mathrm{C}_{0}$ after finding slope of a straight line for all photo-catalysts. The obtained rate constants (k) values are $0.002 \min ^{-1}, 0.004 \min ^{-1}, 0.02 \min ^{-1}, 0.06 \min ^{-1}, 0.08 \min ^{-1}$ and $0.09 \min ^{-1}$ as depicted in Fig.8.

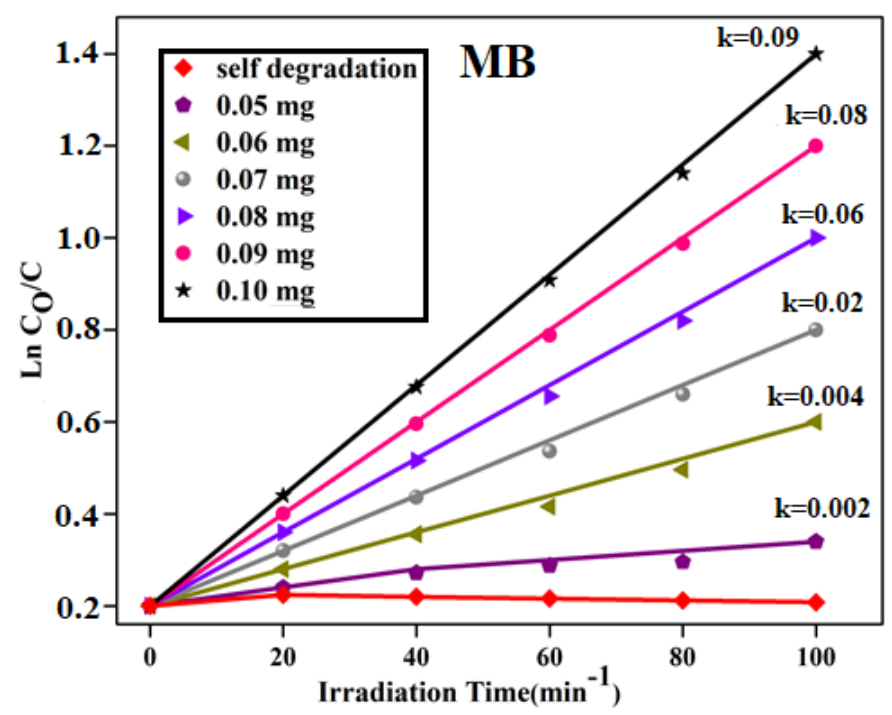

Fig 8: MB graph plotted between the irradiation time and $\ln \mathrm{C}_{0} / \mathrm{C}$ with calculations of $\mathrm{k}$

The graph is plotted between time ( $t$ ) versus $\ln C / C_{0}$ after finding slope of a straight line of photo-catalysts. The pseudo-first-order reaction has been showed the linear curve for all samples, which verified the degradation of Rh-b dye. The calculated values of rate constants $(\mathrm{k})$ are 0.001 $\min ^{-1}, 0.002 \min ^{-1}, 0.003 \min ^{-1}, 0.004 \min ^{-1}, 0.02 \min ^{-1}$ and0.01 $\min ^{-1}$ as depicted in Fig.9. 


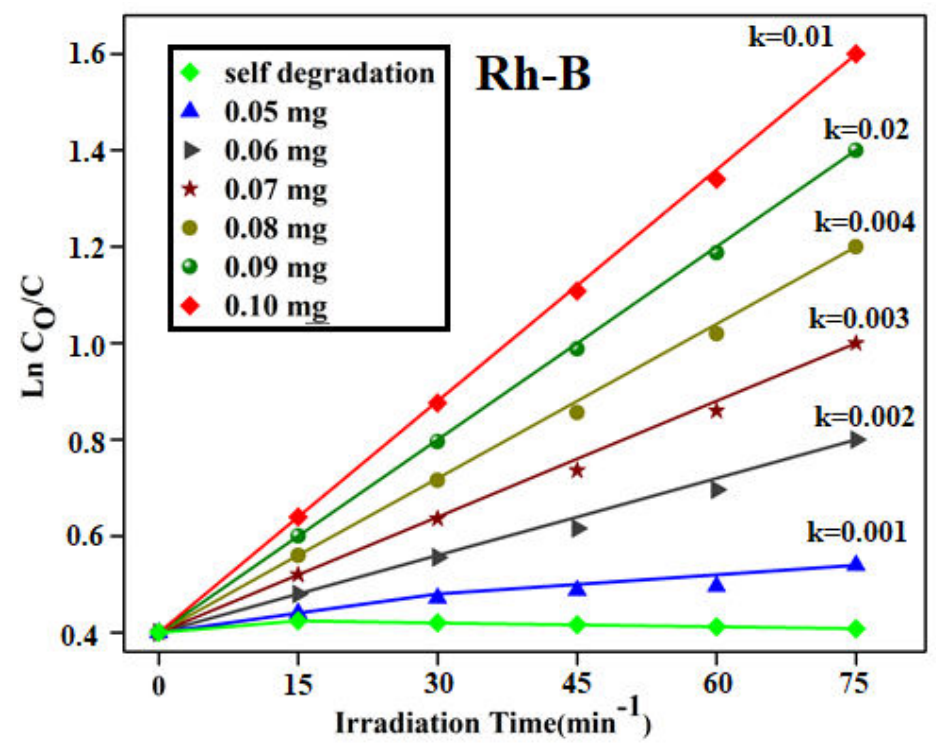

Fig 9: $\mathrm{Rh}-\mathrm{B}$ graph plotted between the irradiation time and $\ln \mathrm{C}_{0} / \mathrm{C}$ with calculations of $\mathrm{k}$.

Photo-catalytic activity with the time variation in organic dyes is depicted in Fig. 10 (a) for MO. The graph plotted between $\mathrm{C}_{0} / \mathrm{C}$ versus time $\mathrm{t}$ in these organic dyes is shown in Fig. 10 (b). Photo-catalysts of $\mathrm{g}-\mathrm{C}_{3} \mathrm{~N}_{4}$ has been degraded $99.9 \%$ in the methylene orange dye (MO) in 70 mints, $96 \%$ methylene blue (MB) in 70 mints and 98\% rhodamine-b (Rh-B) in 70 mints. After comparing the efficiency of these dyes, it could be concluded that $g-\mathrm{C}_{3} \mathrm{~N}_{4}$ nanorods has degraded $\mathrm{MO}$ is the best way with respect to time. The $\mathrm{g}-\mathrm{C}_{3} \mathrm{~N}_{4}$ nanorods catalyst can be effectively used for degradation of $99 \% \mathrm{MO}$ for the industrial wastewater treatment. The graph has been plotted between $\ln \mathrm{C} / \mathrm{C}_{0}$ versus time $\mathrm{t}$ of these dyes for the time variation as depicted in Fig.10 (c). The apparent rate constants value $(\mathrm{K})$ of these dyes for the time variation as shown in Fig $10(\mathrm{~d})$. 


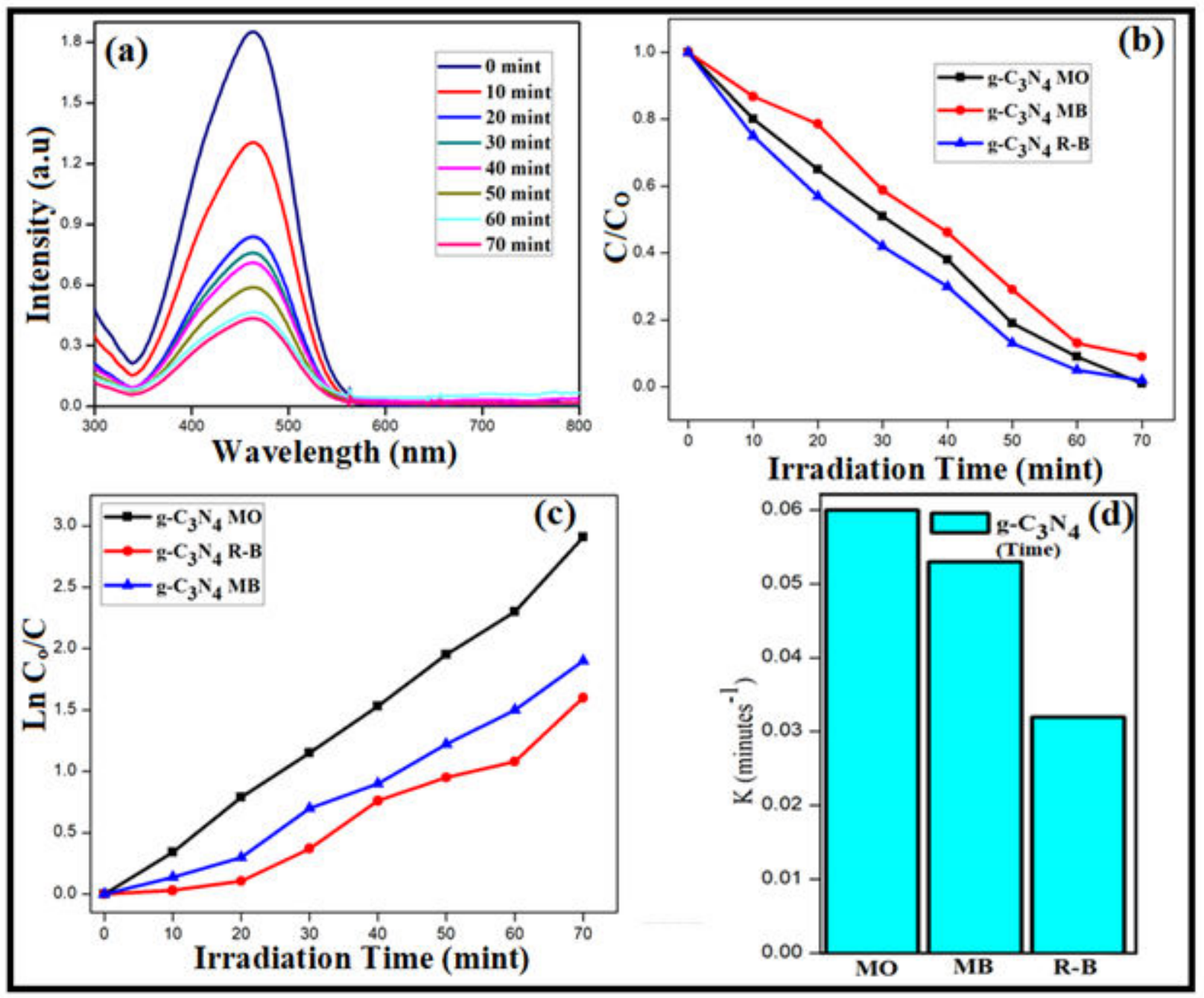

Fig: 10 (a) Photo-catalysis of $\mathrm{MO}(\mathrm{b})$ Graph plotted between the $\mathrm{C} / \mathrm{C}_{0}$ versus irradiation time at $\mathrm{MO}, \mathrm{MB}$ and Rh-B dyes (c) Graph plotted between the $\ln \mathrm{C}_{0} / \mathrm{C}$ versus irradiation time at $\mathrm{MO}$, $\mathrm{MB}$ and $\mathrm{Rh}-\mathrm{B}$ dyes $(\mathrm{d})$ Constant rate reaction $(\mathrm{k})$ values.

The recycling stability of $\mathrm{g}-\mathrm{C}_{3} \mathrm{~N}_{4}$ photo-catalyst is determined under the same conditions for degradation of these organic dyes. It has demonstrated that no noticeable change has occurred in degradation efficiency of the photo-catalyst after five cycles, as shown in Fig 11. 


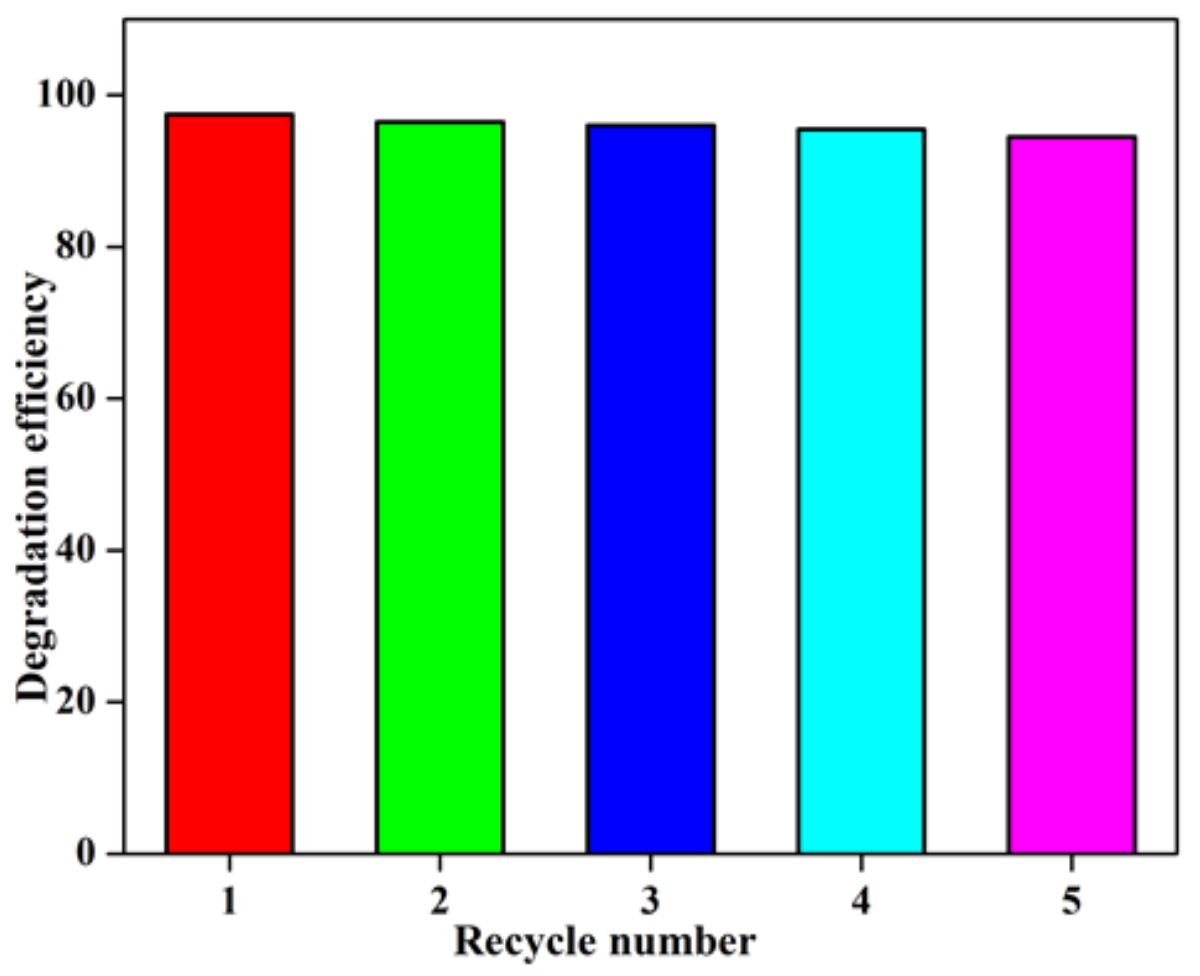

Fig: 11 Cyclic stabilities of $\mathrm{g}-\mathrm{C}_{3} \mathrm{~N}_{4}$ nanorods

\section{The $\mathrm{g}-\mathrm{C}_{3} \mathrm{~N}_{4}$ performance mechanism as a photo-catalyst activity}

Under the UV visible light, the movement of electrons happened in the valence band to conduction band due to fall of photon energy above the surface of $g-\mathrm{C}_{3} \mathrm{~N}_{4}$ in photo-catalytic process. The schematic representation has been demonstrated in Fig 12. The $g-C_{3} N_{4}$ nanorods has played the vital role in degradation process of $\mathrm{MB}, \mathrm{MO}$ and $\mathrm{Rh}-\mathrm{B}$. In the literate review of $\mathrm{Xu}$ and Mo et al [40], the $62.5 \%$ efficiency in MB has been studied at the temperature 600 and $650^{\circ} \mathrm{C}$ respectively. Here, the $\mathrm{g}-\mathrm{C}_{3} \mathrm{~N}_{4}$ nanorods has shown, $99 \%$ degradation efficiency for $\mathrm{MO}$, $96 \%$ efficiency in $\mathrm{MB}$ (time factor) in 70 minutes and $98 \%$ efficiency in $\mathrm{MB}$ (catalyst factor) in 100 minutes has been observed at the temperature of 500 to $550^{\circ} \mathrm{C}$, which indicates comparatively better performance than $\mathrm{Xu}$ and Mo et al [40]. 


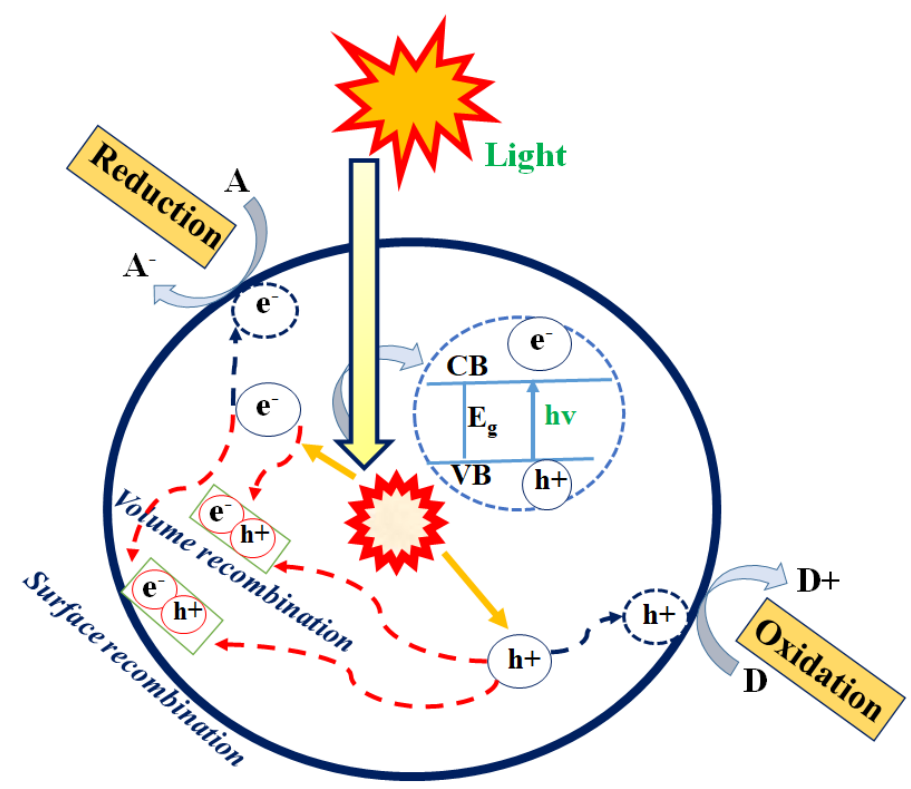

Fig: 12 Schematic diagram photo-catalytic performance of $g-\mathrm{C}_{3} \mathrm{~N}_{4}$

The photocatalytic process for the degradation of organic dyes as depicted in Figure 12. Their corresponding reactions are demonstrated from equations 5 to 16 which are consistent with the literature [39].

As sunlight falls on the photocatalyst and absorbed then following reactions are possible.

$$
\begin{aligned}
& \text { hv }(\text { Energy })+\text { Photocatalyst } \longrightarrow \mathrm{e}^{-} \text {(electron) }+\mathrm{h}^{+} \text {(hole) } \\
& (\text { hole }) \mathrm{h}^{+} \mathrm{H}_{2} \mathrm{O}_{2} \longrightarrow \mathrm{HO}+\mathrm{h}^{+} \\
& \mathrm{O}_{2}^{-}+\mathrm{H}^{+} \longrightarrow \mathrm{HOO}_{2} \mathrm{O}_{2}+\mathrm{O}_{2} \\
& \mathrm{HOO}+\mathrm{HOO} \longrightarrow \mathrm{HO}^{-}+\mathrm{OH}^{-} \\
& (\text {electron }) \mathrm{e}^{-} \mathrm{H}_{2} \mathrm{O}_{2} \longrightarrow \mathrm{HO}^{-}+\mathrm{OH}^{-} \mathrm{O}_{2} \\
& \mathrm{O}_{2}^{-}+\mathrm{H}_{2} \mathrm{O}_{2} \longrightarrow \mathrm{HO}^{\longrightarrow} \\
& (\text { hole }) \mathrm{h}^{+}+\mathrm{OH}^{-} \longrightarrow \mathrm{H}_{2} \mathrm{O}+\mathrm{CO}_{2} \\
& \mathrm{HO}+\text { pollutants } \longrightarrow \mathrm{H}_{2} \mathrm{O}^{+} \mathrm{CO}_{2}
\end{aligned}
$$


It is well known fact that the free radicals have extraordinary oxidizing power which may be used to destroy the harmful organic pollutants like, MO, MB, Rh-B and carboxylic acids [39] [40].

The possible steps containing the photocatalytic reaction mechanism of the organic dyes can be described as in equation 14 to16.

$$
\begin{aligned}
& \mathrm{g}-\mathrm{C}_{3} \mathrm{~N}_{4}[\mathrm{e}-(\mathrm{cb})]+\mathrm{O}_{2} \rightarrow \mathrm{g}-\mathrm{C}_{3} \mathrm{~N}_{4}+\mathrm{O}_{2} \bullet- \\
& \mathrm{g}-\mathrm{C}_{3} \mathrm{~N}_{4}\left[\mathrm{~h}^{+}(\mathrm{vb})\right]+\mathrm{H}_{2} \mathrm{O} \rightarrow \quad \mathrm{g}-\mathrm{C}_{3} \mathrm{~N}_{4}+\cdot \mathrm{OH}+\mathrm{H}^{+} \\
& \mathrm{g}-\mathrm{C}_{3} \mathrm{~N}_{4}\left[\mathrm{~h}^{+}(\mathrm{vb})\right]+\mathrm{OH}^{-} \rightarrow \quad \mathrm{g}-\mathrm{C}_{3} \mathrm{~N}_{4}+\cdot \mathrm{OH}
\end{aligned}
$$

With the absorption of irradiated light, in the presence of the $\mathrm{g}-\mathrm{C}_{3} \mathrm{~N}_{4}$ nanorods as photocatalyst, electrons (e-) will be excited from valence band (VB) to the conduction band (CB) with instant production of holes in the VB in equal number. The photogenerated $\mathrm{e}^{-}$will reacts with surrounding oxygen to generate super oxide radical anion $\left(\mathrm{O}_{2} \bullet-\right)$ in Eq (10). The photogenerated holes in the conduction band react with water and $\cdot \mathrm{OH}$ to form photogenerated hydroxyl radical $(\bullet \mathrm{OH})$ in Eqs (11) and (12). These reactive oxygen species such as $\bullet \mathrm{OH}$ and $\mathrm{O}_{2} \bullet-$ involved in degradation of dye to form degradation products in Eq.(11) and (12).

\section{Conclusion}

In research work, successful synthesis of g- $\mathrm{C}_{3} \mathrm{~N}_{4}$ nano-rods have been performed by using urea through a simple calcination method which has been confirmed by sophisticated techniques such as XRD, TEM, SEM, EDX, PL and UV. The $\mathrm{g}-\mathrm{C}_{3} \mathrm{~N}_{4}$ nano-rods have enhanced photocatalytic properties due to greater active sites which are crucial for photo degradation and waste water treatment. The superior photo-activity of $\mathrm{g}-\mathrm{C}_{3} \mathrm{~N}_{4}$ has been studied in its two factor degradation which are: time variation and catalyst loading. The performance of $\mathrm{g}-\mathrm{C}_{3} \mathrm{~N}_{4}$ towards the three 
primary pollutants revealed noble constancy as a photo-catalytic performer. In the comparison of

these dyes Rh-b, MO and MB, it is concluded that the MO is the best dye to be employed for industrial and societal purposes because it can degrade up to $99.9 \%$ in time variation and $99.7 \%$ in catalyst loading.

\section{Acknowledgment}

The authors extend their appreciation to the deputyship for Research \& Innovation, Ministry of Education in Saudi Arabia for funding this research work through the project number (IFP-202018).

\section{References}

1. Akhundi, A. and A. Habibi-Yangjeh, Novel g-C3N4/Ag2SO4 nanocomposites: fast microwaveassisted preparation and enhanced photocatalytic performance towards degradation of organic pollutants under visible light. Journal of colloid and interface science, 2016. 482: p. 165-174.

2. Akhundi, A. and A. Habibi-Yangjeh, Facile preparation of novel quaternary gC $3 \mathrm{~N} \mathrm{4/Fe} 3 \mathrm{O}$ 4/Agl/Bi 2 S 3 nanocomposites: magnetically separable visible-light-driven photocatalysts with significantly enhanced activity. RSC Advances, 2016. 6(108): p. 106572-106583.

3. Bai, J.Y., et al., Carboxyl functionalized graphite carbon nitride for remarkably enhanced photocatalytic hydrogen evolution. Applied Catalysis B: Environmental, 2020: p. 118590.

4. $\mathrm{Bi}, \mathrm{C}$., et al., Enhanced photocatalytic activity of Bi12017Cl2 through loading Pt quantum dots as a highly efficient electron capturer. Applied Catalysis B: Environmental, 2016. 195: p. 132-140.

5. Chen, X., et al., Fe-g-C3N4-catalyzed oxidation of benzene to phenol using hydrogen peroxide and visible light. Journal of the American Chemical Society, 2009. 131(33): p. 11658-11659.

6. Cheng, J., et al., Drastic promoting the visible photoreactivity of layered carbon nitride by polymerization of dicyandiamide at high pressure. Applied Catalysis B: Environmental, 2018. 232: p. 330-339.

7. Chu, C., et al., Spatially separating redox centers on 2D carbon nitride with cobalt single atom for photocatalytic H2O2 production. Proceedings of the National Academy of Sciences, 2020. 117(12): p. 6376-6382.

8. Fang, H.-B., et al., Fragmented phosphorus-doped graphitic carbon nitride nanoflakes with broad sub-bandgap absorption for highly efficient visible-light photocatalytic hydrogen evolution. Applied Catalysis B: Environmental, 2018. 225: p. 397-405.

9. García-López, E.I., et al., Carbon nitride as photocatalyst in organic selective transformations, in Current Developments in Photocatalysis and Photocatalytic Materials. 2020, Elsevier. p. 437-455.

10. Khamrai, J., et al., Photo-Ni-Dual-Catalytic C (sp2)-C (sp3) Cross-Coupling Reactions with Mesoporous Graphitic Carbon Nitride as a Heterogeneous Organic Semiconductor Photocatalyst. ACS Catalysis, 2020. 10(6): p. 3526-3532.

11. Lee, S. and J.-W. Park, Hematite/Graphitic Carbon Nitride Nanofilm for Fenton and Photocatalytic Oxidation of Methylene Blue. Sustainability, 2020. 12(7): p. 2866. 
12. Li, J., H. Hao, and Z. Zhu, Construction of g-C3N4-WO3-Bi2WO6 double Z-scheme system with enhanced photoelectrochemical performance. Materials Letters, 2016. 168: p. 180-183.

13. Liras, M., M. Barawi, and A. Víctor, Hybrid materials based on conjugated polymers and inorganic semiconductors as photocatalysts: from environmental to energy applications. Chemical Society Reviews, 2019. 48(22): p. 5454-5487.

14. Liu, X., et al., Integrating nitrogen vacancies into crystalline graphitic carbon nitride for enhanced photocatalytic hydrogen production. Chemical Communications, 2020. 56(21): p. 3179-3182.

15. Ma, G., et al., Synergistic effect of $\mathrm{Cu}$-ion and WO3 nanofibers on the enhanced photocatalytic degradation of Rhodamine B and aniline solution. Applied Surface Science, 2018. 451: p. 306314.

16. Ma, H., et al., Preparation of graphitic carbon nitride with large specific surface area and outstanding N2 photofixation ability via a dissolve-regrowth process. Journal of Physics and Chemistry of Solids, 2016. 99: p. 51-58.

17. Malik, R., et al., An excellent humidity sensor based on In-SnO 2 loaded mesoporous graphitic carbon nitride. Journal of Materials Chemistry A, 2017. 5(27): p. 14134-14143.

18. $\mathrm{Xu}, \mathrm{H}$., et al., Synthesis and characterization of gC $3 \mathrm{~N} \mathrm{4/Ag} 2 \mathrm{CO} 3$ with enhanced visible-light photocatalytic activity for the degradation of organic pollutants. RSC Advances, 2014. 4(65): $p$. 34539-34547.

19. Yang, J., et al., Carbon nitrides modified with suitable electron withdrawing groups enhancing the visible-light-driven photocatalytic activity for degradation of the Rhodamine $B$. Materials Research Bulletin, 2018. 106: p. 204-212.

20. Ye, C., et al., Enhanced driving force and charge separation efficiency of protonated g-C3N4 for photocatalytic $O 2$ evolution. Acs Catalysis, 2015. 5(11): p. 6973-6979.

21. Paul, D.R., et al., Effect of calcination temperature, $\mathrm{pH}$ and catalyst loading on photodegradation efficiency of urea derived graphitic carbon nitride towards methylene blue dye solution. RSC advances, 2019. 9(27): p. 15381-15391.

22. Paul, D.R., et al., Silver doped graphitic carbon nitride for the enhanced photocatalytic activity towards organic dyes. Journal of nanoscience and nanotechnology, 2019. 19(8): p. 5241-5248.

23. Su, F.Y., et al., Carbon Self-Doping Induced Activation of $n-\pi^{*}$ Electronic Transitions of g-C3N4 Nanosheets for Efficient Photocatalytic H2 Evolution. ChemCatChem, 2016. 8(22): p. 3527-3535.

24. Tan, H.L., F.F. Abdi, and Y.H. Ng, Heterogeneous photocatalysts: an overview of classic and modern approaches for optical, electronic, and charge dynamics evaluation. Chemical Society Reviews, 2019. 48(5): p. 1255-1271.

25. Tian, J., et al., Remarkably enhanced $\mathrm{H} 2$ evolution activity of oxidized graphitic carbon nitride by an extremely facile K2CO3-activation approach. Applied Catalysis B: Environmental, 2018. 232: p. 322-329.

26. Zhang, J.-H., et al., Ultrathin Graphitic Carbon Nitride Nanosheets for Photocatalytic Hydrogen Evolution. ACS Applied Nano Materials, 2020.

27. Vellaichamy, B. and P. Periakaruppan, Synergistic combination of a novel metal-free mesoporous band-gap-modified carbon nitride grafted polyaniline nanocomposite for decontamination of refractory pollutant. Industrial \& Engineering Chemistry Research, 2018. 57(19): p. 6684-6695.

28. Vinodkumar, T., B.G. Rao, and B.M. Reddy, Influence of isovalent and aliovalent dopants on the reactivity of cerium oxide for catalytic applications. Catalysis Today, 2015. 253: p. 57-64.

29. Zhou, G., et al., A general strategy via chemically covalent combination for constructing heterostructured catalysts with enhanced photocatalytic hydrogen evolution. Chemical communications, 2019. 55(29): p. 4150-4153.

30. Zhou, Y., et al., $\mathrm{N}$-doped graphitic carbon-incorporated g-C3N4 for remarkably enhanced photocatalytic H2 evolution under visible light. Carbon, 2016. 99: p. 111-117. 
31. Vinodkumar, T., et al., Construction of metal oxide decorated gC 3 N4 materials with enhanced photocatalytic performance under visible light irradiation. JOURNAL OF CHEMICAL SCIENCES, 2019. 131(2).

32. Wang, Y., et al., Synthesis of boron doped polymeric carbon nitride solids and their use as metalfree catalysts for aliphatic $C-H$ bond oxidation. Chemical Science, 2011. 2(3): p. 446-450.

33. Wang, Z., et al., Facile synthesis of carbon-rich g-C3N4 by copolymerization of urea and tetracyanoethylene for photocatalytic degradation of Orange II. Journal of Photochemistry and Photobiology A: Chemistry, 2018. 358: p. 61-69.

34. Wu, S.-Z., K. Li, and W.-D. Zhang, On the heterostructured photocatalysts Ag3VO4/g-C3N4 with enhanced visible light photocatalytic activity. Applied Surface Science, 2015. 324: p. 324-331.

35. Xiao, T., et al., In situ construction of hierarchical WO3/g-C3N4 composite hollow microspheres as a Z-scheme photocatalyst for the degradation of antibiotics. Applied Catalysis B: Environmental, 2018. 220: p. 417-428.

36. $\mathrm{Xu}, \mathrm{C} .-\mathrm{Q} ., \mathrm{K} . \mathrm{Li}$, and W.-D. Zhang, Enhancing visible light photocatalytic activity of nitrogendeficient g-C3N4 via thermal polymerization of acetic acid-treated melamine. Journal of colloid and interface science, 2017. 495: p. 27-36.

37. Zhang, Y.-X., et al., Integration of nickel complex as a cocatalyst onto in-plane benzene ringincorporated graphitic carbon nitride nanosheets for efficient photocatalytic hydrogen evolution. Chemical Engineering Journal, 2020. 381: p. 122635.

38. Paul, D.R., et al., ZnO-Modified g-C3N4: A Potential Photocatalyst for Environmental Application. ACS omega, 2020.

39. Nabi, G., et al., Synthesis of g-C3N4 nanorods for visible-light photocatalytic degradation of methylene blue, methylene orange and rhodamine-B. International Journal of Environmental Analytical Chemistry, 2020: p. 1-16.

40. $\mathrm{Xu}, \mathrm{F}$. , et al., Nitrogen-rich graphitic carbon nitride nanotubes for photocatalytic hydrogen evolution with simultaneous contaminant degradation. Journal of colloid and interface science, 2020. 560: p. 555-564. 